\title{
Methodology for developing a web configurator for technology cabinets
}

\author{
Shafik Shaehovich Khuzyatov, Lenar Ajratovich Galiullin \\ Kazan Federal University Naberezhnye Chelny Institute, Rusia
}

\begin{tabular}{l} 
Article Info \\
\hline Article history: \\
Received Dec 9, 2019 \\
Revised Jan 28, 2020 \\
Accepted Feb 7, 2020 \\
\hline
\end{tabular}

Keywords:

Analysis

Cabinet

Manufacturing

Technology

Web

\begin{abstract}
Current trends in the development of Internet technologies are very promising, their role in the functioning of enterprises is increasing significantly. Internet technologies are tools that allow you to interact with potential customers and consumers, receive feedback from them. At the same time, factors of physical remoteness are practically nullified. The situation with the rapid development of the Internet market means that in the process of forming the necessary configurations of technological cabinets for industrial facilities management systems, the use of manual labor should be minimized. The standard approach uses paper media, which leads to a large investment of time in the formation of the necessary configurations and the calculation of their cost. In this regard, increases the complexity of the work performed and the likelihood of errors in the calculations. Thus, the following problems can be formed: the lack of sufficient mechanisms for operational interaction with potential customers; time consuming paper handling; the complexity of the operations; high probability of errors in the calculations; lack of operational access to the necessary information.
\end{abstract}

Copyright (C) 2020 Institute of Advanced Engineering and Science. All rights reserved.

\section{Corresponding Author:}

Lenar Ajratovich Galiullin,

Kazan Federal University Naberezhnye Chelny Institute,

Tel.: 8-906-124-53-18. Rusia.

Email: galilenar@yandex.ru

\section{INTRODUCTION}

The developed system should allow employees and customers of the enterprise to quickly formulate configurations of technological cabinets with a calculation of their cost [1], indicating the required number of sensors and other devices, as well as save the designed configurations for possible future use and refinement [2]. In addition, the system must provide the user with the ability to register and authorize, and the administrator the ability to manage incoming orders, users and the catalog of control panels [3].

Due to the large amount of work that needs to be done to implement this system, its development will be divided into two parts [4]: AIS, which includes a user management system, configurations and panels, and a system for forming configurations of technological cabinets [5]. In this study, problems associated with the system of forming configurations of technological cabinets will be solved [6-10].

Thus, the system should solve the following tasks:

1) Demonstration of a brief description of each control panel;

2) Selection of the appropriate composition of technological cabinets;

3) Interactive calculation of the cost of technological cabinets;

4) Selection of the required number of devices for each panel;

5) Recalculation of the configuration cost, taking into account the number of devices;

6) Creation and removal of technological cabinets, if necessary;

7) Removal of necessary panels from the configuration. 
This system will be relevant and in demand, as potential customers and company employees will be able to form the necessary configuration and access to relevant information regardless of location and time [11-15].

\section{METHODS}

The process of configuring cabinets can be arbitrarily represented as the following operations:

1) Addressing customers to the services of the company in order to form an order for the design of an automated process control system;

2) Viewing by customers and employees of reference information on control panels;

3) Creation of a new or refinement of a previously formed configuration;

4) Selection of the necessary internal composition of technological cabinets;

5) Calculation of the cost of technological cabinet;

6) Determination of the required number of sensors for each panel;

7) Recalculation of the configuration cost, taking into account the necessary sensors;

8) The formation of an order sheet with a list of the configuration with prices;

9) Saving formed during the configuration process;

10) Transfer of information about the formed configuration to ms excel;

11) Creating a schema of the formed configuration in the eplan electric design system based on the ms excel file;

12) If necessary, obtaining an image of the formed configuration, which can be printed.

To describe data streams, the DFD AS-IS ("As is") model is developed [16-20]. Using this model, the sequence of work and information flows will be reflected in the process of configuring cabinets before the implementation and implementation of the automated system [21-26].

The process of configuring cabinets in the context of DFD AS-IS is divided into 5 subprocesses:

a. Receiving orders from customers;

b. Order fulfillment planning;

c. Configuration of technological cabinets;

d. Creating an ms excel file with information about the generated configuration;

e. Creating a circuit in EPLAN Electric based on MS Excel file.

Clients turn to the services of the company in order to form an order for the design of an automated process control system by industrial facilities. Employees of the company register information about customers and automation objects. In accordance with the customer's order and data on the automation object, the company's employees draw up an order fulfillment plan. The simulation took place in the SimInTech system $[9,16]$.

Further, in accordance with the order fulfillment plan and data on the automation object, company employees carry out the configuration of technological cabinets. After that, on the basis of the data on the formed configuration, the company employees create an MS Excel file with information about the formed configuration. In conclusion, based on the MS Excel file with the information about the formed configuration, a circuit is created in the EPLAN Electric design system [27, 28].

\section{RESULTS AND DISCUSSION}

Employees of the company in accordance with the order execution plan, using the available catalog-configurator and on the basis of information about the necessary panels, determine the composition of technological cabinets. Then, based on data on the composition of technological cabinets and information from a catalog with prices on the cost of panels, employees calculate the cost of the configuration. After that, based on the data on the composition of the technological cabinets and the data from the configurator catalog about the sensors and other devices associated with the panels, the number of necessary devices for each panel is determined. Then, based on information from the catalog with prices on the cost of sensors and other devices, company employees recalculate the cost of the configuration. In conclusion, on the basis of data on the cost of the configuration, taking into account sensors and information on the composition of the configuration, company employees draw up an order sheet with prices [11].

The catalog of control panels consists of control sections for various objects, each of which is designed to perform the corresponding functions. Moreover, this system is developed with the calculation of the use of the formed configuration in technological cabinets with the name NT43. Two control panels "Alarm" and "Indicators" are traditionally always present in these technological cabinets and occupy the top two positions. All other panels, as a rule, can occupy any of the remaining 4 positions. In addition, a fixed number of connected devices is associated with each control panel and their types are determined. 
In the automatic process control system, it is used to monitor the emergency state of components and assemblies of various mechanisms, emergency levels in tanks, etc. The panel is designed to integrate equipment with discrete outputs of the type "dry contact" in the ACS TP system. LED indicators show the current status of the input signals that are read by the controller. The ACS TP system traditionally includes discrete signaling, which is used to monitor the emergency state of components and assemblies of various mechanisms, emergency levels in tanks, etc.

Main settings:

1) Number of indicators on the panel -9 ;

2) Number of inputs (sensors, relay contacts) - 8;

3) The position for installation in the acs tp section is the highest, always present;

4) Number of outputs (contacts) -8 .

The panel is designed to integrate sensors with standardized signals $(0-20 \mathrm{~mA}, 4-20 \mathrm{~mA})$ into the automatic process control system and display their values in physical quantities on technological indicators. The current value of the input signals is read by the controller for further processing. The panel provides explosion-proof power supply to sensors, intrinsically safe circuits.

Main settings:

a. Number of technological indicators on the panel -8 ;

b. Number of inputs (sensors) - 8; position for installation in the acs tp section-second from above, always present.

The work of the algorithm begins with data entry: clusters, their main and auxiliary characteristics, relationships between clusters. After testing the system, the following results were obtained:

1. By going to the "Cabinet Configurator" page, one technological cabinet and all related information were automatically added to the order sheet;

2. The panel was transferred from the catalog of control panels to the technological cabinet;

3. Interactively, the panel image was added to the appropriate cabinet and the panel name was added to the "Order List", and the configuration cost was automatically calculated;

4. The "Add" button was pressed;

5. The existing technological cabinet has smoothly shifted to the left, a new technological cabinet has smoothly appeared to the right of it;

6. The panel was transferred from the first cabinet to the second;

7. The names of the panels in the order sheet interactively swapped and the cabinets were automatically recalculated;

8. After left-clicking on the panel, a confirmation window for deletion appears;

9. After confirmation of deletion, this panel was removed from the configuration and the entry for the name of this panel disappeared in the order sheet, and the configuration cost was automatically recalculated;

10. After clicking on the delete icon to the right of the name of the technological cabinet, a confirmation window appears;

11. After confirming the deletion, the image of this cabinet disappeared and all the images of the cabinets located to the right of this cabinet gradually moved to the left;

12. The name of the removed cabinet disappeared from the list in the order sheet and the configuration cost was automatically recalculated;

13. After clicking on the "+" icon to the left of the panel name in the order sheet, there was a smooth disclosure of information about the sensors associated with this panel;

14. After clicking on the icon "in the form of an arrow down," a list appears with available values of the number of sensors;

15. A change was made in the number of sensors in a smaller direction;

16. There was an interactive recalculation of the configuration cost in accordance with the given number of sensors.

Based on the test results, we can say that all the functions of the system work correctly. No errors or incorrect results from user actions were found.

\section{CONCLUSION}

The system is implemented using the JavaScript programming language using the jQuery library and HTML5 page markup language, as well as using the formal language for describing the appearance of CSS3 web pages. The developed system was tested locally and on the server. The results obtained were in line with expectations. 


\section{ACKNOWLEDGEMENTS}

The work is performed according to the Russian Government Program of Competitive Growth of Kazan Federal University

\section{REFERENCES}

[1] R.A. Valiev, A.Kh. Khairullin, V.G. Shibakov, "Automated Design Systems for Manufacturing Processes," Russian Engineering Research, 35(9). pp. 662 - 665, 2015.

[2] Lenar A. Galiullin; Rustam A. Valiev, "Control vector for ice automated test and diagnostic system," dilemas contemporaneos-educacion politica y valores, no. 6 SI, article no. 95, 2018.

[3] Lenar A. Galiullin; Rustam A. Valiev, "Internal combustion engine fault simulation method," iioab journal, no. 9, pp. 91-96, 2018.

[4] Lenar A. Galiullin; Rustam A. Valiev, Khairullin A. Haliullovich, "Method for modeling the parameters of the internal combustion engine," Iioab Journal, no. 9, pp. 83-90, 2018.

[5] V.V. Bukhtoyarov, V.S. Tynchenko, E.A. Petrovskiy, V.V. Tynchenko, and V.G. Zhukov, "Improvement of the methodology for determining reliability indicators of oil and gas equipment, "International Review on Modelling and Simulations, Vol. 11 (1), pp. 37-50, 2018.

[6] V.S. Tynchenko, V.V. Kukartsev, V.V. Tynchenko, E.A. Chzhan, and L.N. Korpacheva, "Automation of monitoring and management of conveyor shop oil-pumping station of coal industry enterprise," IOP Conference Series: Earth and Environmental Science, Vol. 194(2), 2018, Article number 022044.

[7] S.A. Sobolev and R.B. Fattakhov, "Coordination of booster pump stations operating modes," Oil Industry, no. 6, pp. 122-125, 2013.

[8] Kovalchuk, Aleksander K., and Faniya Kh Akhmetova. "Denavit-Hartenberg Coordinate System for Robots with Tree-like Kinematic Structure." International Journal of Robotics and Automation (IJRA) 5, no. 4: 244-254, 2016.

[9] N.G. Ibragimov, R.G. Zabbarov, and V.R. Idiatova, "Operational supervision and oil production control system based on monitoring of telemetry-controlled well performance in ARMITS corporate information system," Oil Industry, no. 4, pp. 106-109, 2014.

[10] B.A. Kartashov, E.A. Shabaev, O.S. Kozlov, A.M. Shchekaturov "Dynamic modeling environment for technical systems SimInTech," Moscow: DMK Press, 2017. - pp. 423.

[11] S.S. Khuzyatov and R.A. Valiev, "Organization of data exchange through the Modbus network between the SIMATIC S7 PLC and field devices," in Proc. International Conference on Industrial Engineering, Applications and Manufacturing, ICIEAM, 2017, Article number 8076369.

[12] X. Chen, Y. Che, and K.W.E. Cheng, "PLC and configuration software based supervisory and control system for oil tanks area," in Proc. Power Electronics Systems and Applications, 2009, Article number 5228628.

[13] S.-A. Tcaciuc, "Performances Analysis of a SCADA Architecture for Industrial Processes," International journal of advanced computer science and applications, Vol. 8, Iss. 11, pp. 456-460, 2017.

[14] Raheem, Enas A., Sharifah Mumtazah Syed Ahmad, and Wan Azizun Wan Adnan. "Insight on face liveness detection: A systematic literature review." International Journal of Electrical \& Computer Engineering (2088-8708) 9, 2019.

[15] J. Reeser, T. Jankowski, and G.M. Kemper, "Maintaining HMI and SCADA systems through computer virtualization," IEEE Transactions on Industry Applications, vol. 51, no. 3, pp. 2558-2564, May 2015.

[16] R. Butta, "An overview of oil drilling and production monitoring system using SCADA automation in Oiland Natural Gas Corporation Ltd," in Proc. Electrical, Electronics, Signals, Communication and Optimization, September 2015, Article number 7253920.

[17] Sh.Sh. Khuzyatov and R.A. Valiev, "Desining of automated control systems based on pattern methods," Scientific and Technical Bulletin of the Volga Region, no. 2, pp. 215-218, 2015.

[18] Baum F.I., "SimInTech software for programming control system devices / F.I. Baum, O.S. Kozlov, I.A. Parshikov, V.N. Petukhov, K.A. Timofeev, A.M. Shchekaturov," Atomic energy, 2012.V.113. no. 6 P.354-357.

[19] A.N. Iliukhin, S.S. Khuzyatov, and R.A. Valiev, "Unified approach to software development of automated control systems for oil equipment," HELIX, vol. 8, no. 1, pp. 2455-2459, 2017.

[20] R.A. Valiev and S.S. Khuzyatov, "Pattern-design software of automated control systems," in Proc. 2nd International Conference on Industrial Engineering, Applications and Manufacturing, ICIEAM, 2016, Article number 7910942.

[21] Bin Kassim, Muhammad Fuad, and Mohd Norzali Haji Mohd. "Food intake gesture monitoring system based-on depth sensor." Bulletin of Electrical Engineering and Informatics 8, no. 2, pp. 470-476, 2019.

[22] A. Belousov, Y. Koshlich, A. Grebenik, and I. Gvozdevskiy, "An approach of lower-level communication line implementation of automated dispatch control systems of distributed facilities," in Proc. International Multidisciplinary Scientific GeoConference Surveying Geology and Mining Ecology Management, SGEM, Vol. 17 (21), pp. 183-190, 2017.

[23] S.S. Khuzyatov and R.A. Valiev, "The software template engineering for the utilization system of associated petroleum gas in a gas turbine plant," in Proc. 2018 International Conference on Industrial Engineering, Applications and Manufacturing, ICIEAM, in press.

[24] Q.-C. Wang and L.-K. Hu, "Research on WinCC-based SCADA software for acrylic fibres filature," Huagong Zidonghua Ji Yibiao, Control and Instruments in Chemical Industry, Vol. 33(1), pp. 35-38, 2006. 
[25] H. Berger, "Automating with Simatic: Controllers, Software, Programming, Data Communication, Operator Control and Process Monitoring," Erlangen: Publicis Publishing, 2013.

[26] R.F. Liao, C.W. Chan, J. Hromek, G.H. Huang, and L. He, "Fuzzy logic control for a petroleum separation process," Engineering Applications of Artificial Intelligence, Vol. 21 (6), pp. 835-845, 2008.

[27] R. Liao, C.W. Chan, and G.G. Huang, "A fuzzy logic controller for an oil separation process," Canadian Conference on Electrical and Computer Engineering, Article number 1557155, pp. 1045-1048, 2005.

[28] Ranjbari, M. H., Shaheri, A., Dalili, R., \& Soroush, R. (2015). Optimal allocation of distributed generation using an analytical method with consideration of technical and economic parameters. UCT Journal of Research in Science, Engineering and Technology, 3(1), 9-17.

\section{BIOGRAPHIES OF AUTHORS}

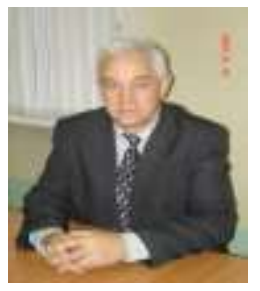

Shafik Shaehovich Khuzyatov, Date of Birth:09/03/1956 Education: 1981-1984 higher education: Kazan State University, mechanics and mathematics, mechanics. Qualification: mechanic. Positions: Associate Professor (Associate Professor), Naberezhnye Chelny Institute (branch) KFU/Higher Engineering School/Department of Information Technology and Energy Systems/Department of Information Systems, NI (main employee). Academic degrees: Candidate (technical sciences) (12/27/1993), specialty 05.13.01-System analysis, management and information processing (by industry), title of the dissertation "Stability of systems with distributed parameters with a delayed argument and an application to the study of the stability of elastic wing oscillations"

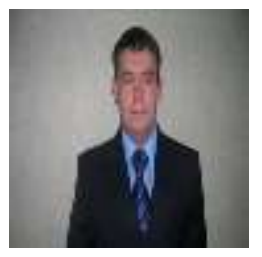

Lenar Ajratovich Galiullin, Associate Professor (Associate Professor), Naberezhnye Chelny Institute (branch) KFU/Higher Engineering School/Department of Information Technology and Energy Systems / Department of Information Systems, NI (internal part-time). Academic degrees: $\begin{array}{lllll}\text { Candidate } & \text { (technical } & \text { sciences) } & \text { (December } & \text { 29, }\end{array}$ specialty 05.13.06-Automation and control of technological processes and production (by industry), the title of the dissertation "Automation of the technological process of diesel testing based on the fuzzy neural network method" 